\title{
FACILE SYNTHESIS AND CRYSTAL STRUCTURE OF 1,5-DIMETHYL-6-THIOXO-1,3,5-TRIAZINANE-2,4-DIONE
}

\author{
N. Shajari ${ }^{1}$, A.R. Kazemizadeh ${ }^{1}$, A. Ramazani ${ }^{1}$, S.W. Joo ${ }^{2}$, \\ K. Ś le pokura ${ }^{3}$, T. Lis ${ }^{3}$,A. Souldozi \\ ${ }^{1}$ Research Laboratory of MCRs, Department of Chemistry, Zanjan Branch, Islamic Azad University, Zanjan, \\ Iran \\ E-mail: aliramazani@gmail.com (A. Ramazani) \\ ${ }^{2}$ School of Mechanical Engineering, Yeungnam University, Gyeongsan, Republic of Korea \\ E-mail: swjoo@yu.ac.kr (S.W.Joo) \\ ${ }^{3}$ Faculty of Chemistry, University of Wroctaw, Wroctaw, Poland \\ ${ }^{4}$ Department of Chemistry, Urmia Branch, Islamic Azad University, Urmia, Iran
}

Received October 21, 2013

\begin{abstract}
The title compound 1,5-dimethyl-6-thioxo-1,3,5-triazinane-2,4-dione $\mathrm{C}_{5} \mathrm{H}_{7} \mathrm{~N}_{3} \mathrm{O}_{2} \mathrm{~S}$ is synthesized via the reaction between $\mathrm{N}, \mathrm{N}^{\prime}$-dimethylthiourea and trichloroacetyl isocyanate in dichloromethane. The structure of the title compound is characterized by IR, ${ }^{1} \mathrm{HNMR},{ }^{13} \mathrm{C} \mathrm{NMR}$, elemental analysis, and single-crystal X-ray diffraction. The crystal structure reveals the role of $\mathrm{N}-\mathrm{H} \cdots \mathrm{O}$ and $\mathrm{C}-\mathrm{H} \cdots \mathrm{O}$ hydrogen bonds, and $\mathrm{C}=\mathrm{O} \cdots \pi$ interactions in the arrangement of the molecules into ribbons, which are further joined to each other to form double-layers parallel to the (001) plane.
\end{abstract}

DOI: $10.15372 / \mathrm{JSC} 20150433$

K e y w o r d s: N,N'-dimethylthiourea, trichloroacetyl isocyanate, triazinane, X-ray diffraction.

Heterocyclic compounds have great importance in the biological and medicinal sciences and thus there are many efforts for the development of new efficient and mild synthetic routes for their synthesis [ 1,2 ]. Triazine derivatives have fungicide [3 ], antiplasmodial [4], anti-HIV [5], and herbicidal [6] activities. They also have application in protection of amino groups [7] as well as for the synthesis of polyamines [8] and polyfunctional amino alcohols [7]. In connection with our interest to the synthesis of heterocycles [9-13], we report the reaction between $\mathrm{N}, \mathrm{N}^{\prime}$-dimethylthiourea (1) and trichloroacetyl isocyanate (2) to produce 1,5-dimethyl-6-thioxo-1,3,5-triazinane-2,4-dione (3). The crystal structure of $\mathbf{3}$ was determined by X-ray diffraction. Compound (3) was synthesized long ago [14 ], however in the Cambridge structural database there are no data on the structure of neutral 6-thioxo1,3,5-triazinane-2,4-dione derivatives [ 14 ].

Experimental. Materials and apparatuses. Starting materials and solvents were obtained from Merck (Germany) and Fluka (Switzerland) and were used without further purification. Melting points were measured on an electrothermal 9100 apparatus and were uncorrected. IR spectra were measured on a Jasco FT-IR 6300 spectrometer. ${ }^{1} \mathrm{H}$ and ${ }^{13} \mathrm{C}$ NMR spectra were measured $\left(\mathrm{CDCl}_{3}\right.$ solution) with a BRUKER DRX-250 AVANCE spectrometer at $250.0 \mathrm{MHz}$ and $62.5 \mathrm{MHz}$ respectively. Elemental analyses were performed using a Heraeus $\mathrm{CHN}-\mathrm{O}-$ rapid analyzer.

(C) Shajari N., Kazemizadeh A.R., Ramazani A., Joo S.W., Ślepokura K., Lis T., Souldozi A., 2015 


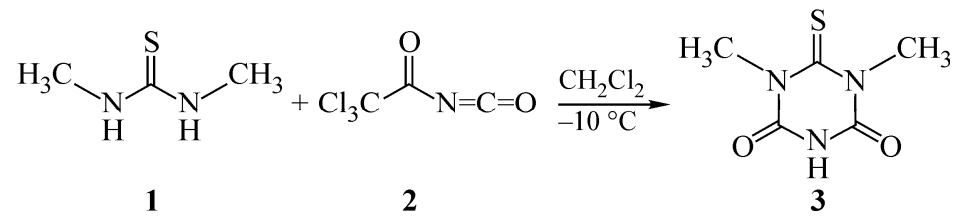

Scheme 1. Synthesis of 1,5-dimethyl-6-thioxo-1,3,5-triazinane-2,4-dione

Synthesis and characterization of compound 3. Title compound 3 was synthesized by the method depicted in Scheme 1. To a magnetically stirred solution of trichloroacetyl isocyanate 2

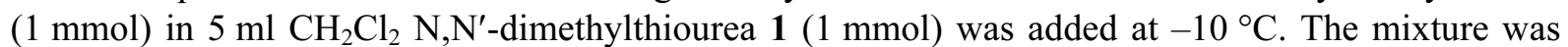
stirred at room temperature for $4 \mathrm{~h}$. Then the mixture was filtered and washed with $\mathrm{CH}_{2} \mathrm{Cl}_{2}$. The remaining white solid was dissolved in $5 \mathrm{ml}$ chloroform and refluxed for $8 \mathrm{~h}$. The solvent was removed under reduced pressure and washed with $\mathrm{CH}_{2} \mathrm{Cl}_{2}$. Single crystals were obtained by slow evaporation using a $n$-heptane/chloroform $(1: 4, \mathrm{v} / \mathrm{v})$ solvent system.

Yield $80 \%$, white powder, m.p. $190.1 \sim 191.2{ }^{\circ} \mathrm{C}$, Anal. Calcd. (\%) for $\mathrm{C}_{5} \mathrm{H}_{7} \mathrm{~N}_{3} \mathrm{O}_{2} \mathrm{~S}$ (173.19): $\mathrm{C}$, 34.67; H, 4.07; N, 24.26. Found (\%): C, 34.62; H, 4.10; N, 24.29. IR (KBr) $v / \mathrm{cm}^{-1}: 3249(\mathrm{NH})$, 1712(C=O), 1465, 1119, 764. ${ }^{1} \mathrm{H}$ NMR $\left(250 \mathrm{MHz}, \mathrm{CDCl}_{3}\right) \delta / \mathrm{ppm}: 3.69\left(s, 6 \mathrm{H}, 2 \mathrm{CH}_{3}\right), 9.54(\mathrm{bs}, 1 \mathrm{H}$,

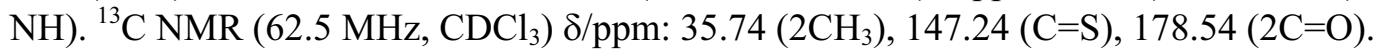

Crystal structure determination. The crystallographic measurement was performed on an Oxford Diffraction Xcalibur with a PX א-geometry four-circle diffractometer with graphite-monochromatized $\mathrm{Mo} K_{\alpha}$ radiation. The data were collected at 120(2) K using an Oxford Cryosystems cooler. Data collection, cell refinement, and data reduction and analysis were carried out with the Xcalibur PX software, CRYSALIS CCD, and CRYSALIS RED respectively [ 15 ]. Empirical absorption correction was applied to the data with the use of CRYSALIS RED. The structures were solved by direct methods using the SHELXS-97 program [16] and refined by a full-matrix least-squares technique based on $F^{2}$ using SHELXL-97 [16] with anisotropic thermal parameters for the non-H-atoms. The $\mathrm{H}$ atoms were found in difference Fourier maps and were refined isotropically. The figures presenting the molecular and crystal structures were made using the DIAMOND program [17]. CCDC-886361 contains the supplementary crystallographic data for 3 . These data can be obtained free of charge via http://www.ccdc.cam.ac.uk/data_request/cif.

Crystal data for (3). $\mathrm{C}_{5} \mathrm{H}_{7} \overline{\mathrm{N}}_{3} \mathrm{O}_{2} \mathrm{~S}, M=173.20$, colorless block, crystal size $0.34 \times 0.28 \times 0.18 \mathrm{~mm}$, monoclinic, space group $P 2_{1} / n$ (no. 14), $a=7.249(2) \AA, b=7.357(2) \AA, c=14.082(4) \AA, \beta=100.76(4)^{\circ}$, $V=737.8(4) \AA^{3}, T=120(2) \mathrm{K}, Z=4, \rho_{\text {calc }}=1.559 \mathrm{~g} / \mathrm{cm}^{3}, \mu=0.39 \mathrm{~mm}^{-1}$ (for $\mathrm{MoK}_{\alpha}, \lambda=0.71073 \AA$ ), absorption correction: multi-scan, $T_{\min }=0.947, T_{\max }=1.000,14990$ reflections measured, 4030 unique $\left(R_{\text {int }}=0.021\right), 3273$ observed $(I>2 \sigma(I)), \theta$ range $4.43-38.53^{\circ}$, parameters $=128$, restraints $=0$, $R_{1}=0.030, w R_{2}=0.086$ (observed refl.), GOOF $=S=1.08$, largest difference in peak and hole, $\Delta \rho_{\max }$ and $\Delta \rho_{\min }=0.49$ and $-0.34 \mathrm{e} / \AA^{3}$.

Results and discussion. The reaction between 1 and 2 led to 3. The ${ }^{1} \mathrm{H} N M R,{ }^{13} \mathrm{C} N M R$, and IR for the product are in good agreement with the title compound.

The structure of compound $\mathbf{3}$ was also confirmed by a single crystal X-ray structure determination (Fig. 1). This $\mathrm{N}, \mathrm{N}^{\prime}$-dimethylthiocyanuric acid is a planar molecule (with an r.m.s. deviation of fitted non-H atoms $=0.029 \AA$ ). The values of bond lengths and valence angles (Table 1) correspond well with those typical of the respective types of chemical bonds [18 ]. It should be noted that the bond lengths are also very

Fig. 1. View of the molecule of $\mathbf{3}$ with the atom-numbering scheme. Displacement ellipsoids are drawn at the $50 \%$ probability level

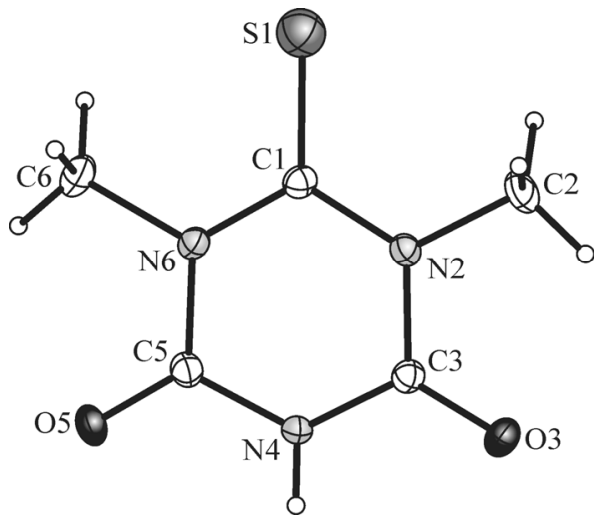


Selected geometric parameters $(\AA$, deg.) for $\mathbf{3}$

\begin{tabular}{l|l|l|l||ll|l}
\hline \multicolumn{3}{c|}{ Bond lengths } & \multicolumn{5}{|c}{ Bond angles } \\
\hline $\mathrm{S}(1)-\mathrm{C}(1)$ & $1.6548(7)$ & $\mathrm{C}(1)-\mathrm{N}(2)-\mathrm{C}(2)$ & $119.17(6)$ & $\mathrm{N}(6)-\mathrm{C}(1)-\mathrm{S}(1)$ & $121.76(5)$ \\
$\mathrm{O}(3)-\mathrm{C}(3)$ & $1.2186(8)$ & $\mathrm{C}(1)-\mathrm{N}(2)-\mathrm{C}(3)$ & $123.67(5)$ & $\mathrm{N}(2)-\mathrm{C}(1)-\mathrm{N}(6)$ & $116.36(5)$ \\
$\mathrm{O}(5)-\mathrm{C}(5)$ & $1.2212(8)$ & $\mathrm{C}(2)-\mathrm{N}(2)-\mathrm{C}(3)$ & $116.75(6)$ & $\mathrm{O}(3)-\mathrm{C}(3)-\mathrm{N}(2)$ & $122.88(6)$ \\
$\mathrm{N}(2)-\mathrm{C}(1)$ & $1.3782(9)$ & $\mathrm{C}(5)-\mathrm{N}(4)-\mathrm{C}(3)$ & $125.72(6)$ & $\mathrm{O}(3)-\mathrm{C}(3)-\mathrm{N}(4)$ & $122.03(6)$ \\
$\mathrm{N}(2)-\mathrm{C}(2)$ & $1.4696(9)$ & $\mathrm{C}(1)-\mathrm{N}(6)-\mathrm{C}(5)$ & $123.37(6)$ & $\mathrm{N}(4)-\mathrm{C}(3)-\mathrm{N}(2)$ & $115.09(6)$ \\
$\mathrm{N}(2)-\mathrm{C}(3)$ & $1.3901(9)$ & $\mathrm{C}(1)-\mathrm{N}(6)-\mathrm{C}(6)$ & $119.10(5)$ & $\mathrm{O}(5)-\mathrm{C}(5)-\mathrm{N}(4)$ & $121.41(6)$ \\
$\mathrm{N}(4)-\mathrm{C}(3)$ & $1.3688(9)$ & $\mathrm{C}(5)-\mathrm{N}(6)-\mathrm{C}(6)$ & $117.25(6)$ & $\mathrm{O}(5)-\mathrm{C}(5)-\mathrm{N}(6)$ & $123.11(6)$ \\
$\mathrm{N}(4)-\mathrm{C}(5)$ & $1.3663(9)$ & $\mathrm{N}(2)-\mathrm{C}(1)-\mathrm{S}(1)$ & $121.88(5)$ & $\mathrm{N}(4)-\mathrm{C}(5)-\mathrm{N}(6)$ & $115.48(6)$ \\
$\mathrm{N}(6)-\mathrm{C}(1)$ & $1.3827(9)$ & & & & \\
$\mathrm{N}(6)-\mathrm{C}(5)$ & $1.3850(9)$ & & & & \\
$\mathrm{N}(6)-\mathrm{C}(6)$ & $1.4733(9)$ & &
\end{tabular}

close to the corresponding bond lengths of 2-(2,4-dioxo-6-thioxo-(1,3,5)triazinan-1-yl)ethylammonium chloride and bromide salts [19].

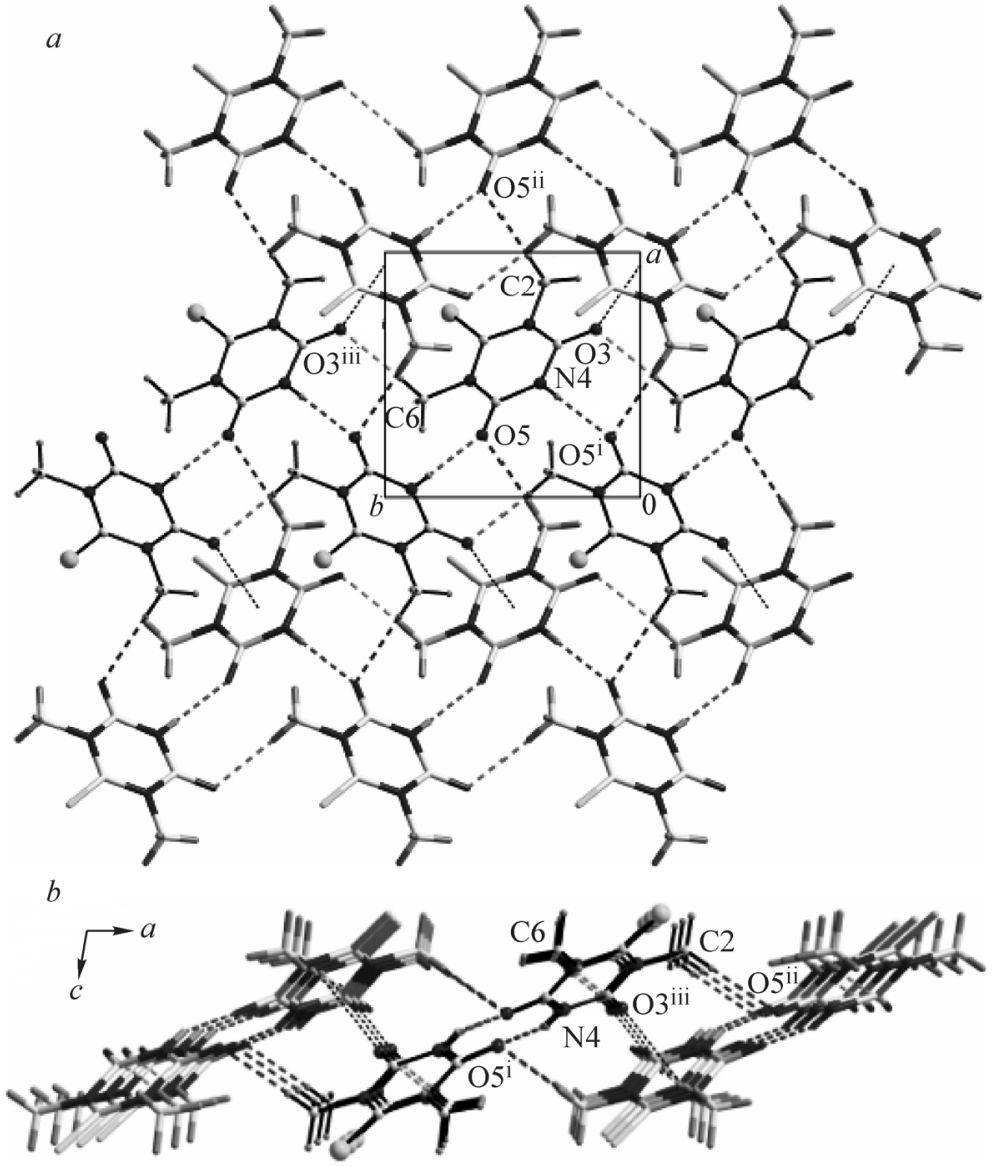

Fig. 2. Three ribbons (shown with different styles) joined via the inter-ribbon $\mathrm{C}-\mathrm{H} \cdots \mathrm{O}$ and $\mathrm{C}=\mathrm{O} \cdots \pi$ interactions to form doublelayers parallel to (001) plane in the crystal of $\mathbf{3}$.

Viewed down the $c$ axis $(a)$ and $b$ axis $(b)$. Symmetry codes are given in Table 2 


\begin{tabular}{c|c|c|c|c}
\multicolumn{5}{c}{ Hydrogen bond geometry $(\AA$, deg. $)$ for $(3)$} \\
\hline$D-\mathrm{H} \cdots A$ & $D-\mathrm{H}, \AA$ & $\mathrm{H} \cdots A, \AA$ & $D \cdots A, \AA$ & $D-\mathrm{H} \cdots A$, deg. \\
\hline $\mathrm{N} 4-\mathrm{H} 4 \cdots \mathrm{O} 5^{\mathrm{i}}$ & $0.83(2)$ & $2.10(2)$ & $2.895(1)$ & $159(2)$ \\
$\mathrm{C} 2-\mathrm{H} 2 C \cdots \mathrm{O} 5^{\mathrm{ii}}$ & $0.97(2)$ & $2.47(2)$ & $3.440(2)$ & $179(1)$ \\
$\mathrm{C} 6-\mathrm{H} 6 A \cdots \mathrm{O} 3^{\mathrm{iii}}$ & $0.96(2)$ & $2.38(2)$ & $3.337(2)$ & $176(2)$
\end{tabular}

Symmetry codes: (i) $-x+1 / 2, y-1 / 2,-z+3 / 2$; (ii) $x+1, y, z$; (iii) $x$, $y+1, z$.

The crystal structure of (3) is stabilized by a network of intermolecular $\mathrm{N}-\mathrm{H} \cdots \mathrm{O}$ and $\mathrm{C}-\mathrm{H} \cdots \mathrm{O}$ hydrogen bonds and $\mathrm{C}=\mathrm{O} \cdots \pi$ interactions linking the adjacent molecules (Fig. 2, Table 2). Ribbons along the $b$ axis are generated by means of $\mathrm{N}-\mathrm{H} \cdots \mathrm{O}$ and $\mathrm{C}-\mathrm{H} \cdots \mathrm{O}$ contacts linking the adjacent molecules in a manner shown in Fig. 2. This combination of the action of $2_{1}$ screw axis and a direct $b$ axis translation gives rise to $R_{3}^{3}(13)$ rings within the ribbon.

As shown in Fig. 2, the adjacent ribbons, related by a direct $a$ axis translation are linked to each other via other $\mathrm{C}-\mathrm{H} \cdots \mathrm{O}$ interactions to form double-layers parallel to the (001) plane, at $z=1 / 4,3 / 4$, ... Within the inter-ribbon contacts there are also $\mathrm{C}=\mathrm{O} \cdots \pi$ interactions (dotted lines in Fig. 2) with an $\mathrm{O} \cdots C g(1)$ distance of $2.794(1) \AA$, perpendicular to the $\mathrm{O} \cdots$ ring separation of $2.749 \AA, \mathrm{C}=\mathrm{O} \cdots C g(1)$ angle of $142.28(6)^{\circ}$ and $C \cdots C g(1)=3.831(2) \AA[C g(1)$ is the ring centroid].

This work was supported by Grant 2011-0014246 of the National Research Foundation of Korea.

\section{REFERENCES}

1. Lichtenthaler F.W. // Acc. Chem. Res. - 2002. - 35. - P. 728 - 737.

2. Litvinov V.P. // Russ. Chem. Rev. - 2003. - 72. - P. $69-85$.

3. Ibrahim M.A., Abdel-Rahman R.M., Abdel-Halim A.M., Ibrahim S.S., Allimony H.A. // J. Braz. Chem. Soc. -2009. - 20. - P. 1275 - 1286.

4. Klenke B., Barrett M.P., Brun R., Gilbert I.H. // J. Antimicrob. Chemother. - 2003. - 52. - P. 290 - 293.

5. Patel R.B., Chikhalia K.H., Pannecouque C., Clercq E. // J. Braz. Chem. Soc. - 2007. - 18. - P. 312 - 321.

6. Soong C.L., Ogawa J., Sakuradani E., Shimizu S. // J. Biol. Chem. - 2002. - 277. - P. 7051 - 7058.

7. Wakefield B.J., Wright D.J. // Adv. Heterocycl. Chem. - 1979. - 25. - P. 147 - 204.

8. Kashima C. // Heterocycles. - 1979. - 12. - P. 1343 - 1368.

9. a) Ramazani A., Morsali A., Ganjeie B., Kazemizadeh A.R., Ahmadi E., Kempe R., Hertle I. // Z. Naturforsch. - 2005. - 60b. - P. 569 - 571. b) Ramazani A., Ahmadi Y., Rouhani M., Shajari N., Souldozi A. // Heteroat. Chem. - 2010. - 21. - P. 368 - 372. c) Kazemizadeh A.R., Hajaliakbari N., Hajian R., Shajari N., Ramazani A. // Helv. Chim. Acta. - 2012. - 95. - P. 594 - 597.

10. a) Ramazani A., Shajari N., Mahyari A., Ahmadi Y. // Mol. Divers. - 2011. - 15. - P. 521 - 527. b) Ramazani A., Rouhani M., Rezaei A., Shajari N., Souldozi A. // Helv. Chim. Acta. - 2011. - 94. - P. 282 - 288. c) Ramazani A., Rezaei A. // Org. Lett. - 2010. - 12. - P. 2852 - 2855.

11. a) Ramazani A., Marandi F., Kazemizadeh A.R. // Phosphorus, Sulfur Silicon Relat. Elem. - 2005. - 180. - P. 1541 - 1544. b) Ganjeie B., Ramazani A., Kazemizadeh A.R. // Phosphorus, Sulfur Silicon Relat. Elem. - 2007. - 182. - P. 1703 - 1708. c) Ramazani A., Ahmadi E., Kazemizadeh A.R., Dolatyari L., Noshiranzadeh N., Eskandari I., Souldozi A. // Phosphorus, Sulfur Silicon Relat. Elem. - 2005. - 180. - P. 2419 2422 .

12. a) Ramazani A., Morsali A., Ganjeie B., Kazemizadeh A.R., Ahmadi E. // Phosphorus, Sulfur Silicon Relat. Elem. - 2005. - 180. - P. 2439 - 2442. b) Rahnema M., Bigdeli M.R., Kazemizadeh A.R., Ramazani A. // Phosphorus, Sulfur Silicon Relat. Elem. - 2007. - 182. - P. 1683 - 1688. c) Ramazani A., Kazemizadeh A.R., Ganjeie B., Ahmadi E. // Phosphorus, Sulfur Silicon Relat. Elem. - 2005. - 180. - P. 2569 - 2572. 
13. a) Ramazani A., Souldozi A., Marandi F., Kazemizadeh A.R. // Asian J. Chem. - 2005. - 17. - P. 293 - 296.

b) Ramazani A., Ahmadi E., Ganjeie B., Kazemizadeh A.R., Morsali A. // Asian J. Chem. - 2005. - 17. - P. 2371 - 2374. c) Ramazani A., Kazemizadeh A.R., Ganjeie B., Ahmadi E. // Asian J. Chem. - 2005. - 17. - P. 2375 - 2378. d) Souldozi A., Ramazani A. // Tetrahedron Lett. - 2007. - 48. - P. 1549 - 1551. e) Souldozi A., Ramazani A., Bouslimani N., Welter R. // Tetrahedron Lett. - 2007. - 48. - P. 2617 - 2620.

14. Tosato M.L. // J.C.S. Perkin II. - 1979. - N 10. - P. 1371 - 1375.

15. CRYSALIS CCD and CRYSALIS RED in Xcalibur PX Software, Oxford Diffraction Ltd, Abingdon, England, 2009.

16. Sheldrick G.M. // Acta Crystallogr. - 2008. - A64. - P. 112 - 122.

17. Brandenburg K. DIAMOND. Ver. 3.0d. Crystal Impact GbR, Bonn, Germany, 2005.

18. Allen F.H., Kennard O., Watson D.G., Brammer L., Orpen A.G., Taylor R. // J. Chem. Soc. Perkin Trans. II. - 1987. - P. S1 - S19.

19. Frontera A., Saczewski F., Gdaniec M., Dziemidowicz-Borys E., Kurland A., Deyà P.M., Quiñonero D., Garau C. // Chem-Eur. J. - 2005. - 11. - P. 6560-6567. 